\title{
Compromiso y esperanza en educación: Los ejes transversales para la práctica docente según Paulo Freire
}

\section{Commitment and hope in education: Cross-curricular themes for teaching practices according to Paulo Freire}

\author{
José Ángel García-Retana ${ }^{1}$ \\ Universidad de Costa Rica \\ Sede Guanacaste \\ Guanacaste, Costa Rica \\ jose.garcia@ucr.ac.cr
}

Recibido: 26 mayo 2014 Aceptado: 25 junio 2015 Corregido: 19 julio 2015

\begin{abstract}
Resumen: Pedagogía de la autonomía es un texto donde Freire aborda cómo todo acto educativo es un acto político e ideológico, condicionado pero no determinado, que va más allá de la simple transmisión de conocimientos. Considera los saberes requeridos para la práctica docente y detalla al menos cinco ejes transversales: la relación dialéctica entre aprender y enseñar, la importancia de tomar en cuenta los aspectos emocionales, el carácter político que encierra, enseñar es más que transmitir información y el compromiso ético del personal docente. Aduce que la práctica educativa como acto político es deliberado y depende de la visión de mundo (ideología) que tenga cada docente. Tal acto debe conllevar el desarrollo de una intencionalidad: la autonomía del educando. Freire prevé el proceso de globalización y el impacto de las tecnologías digitales en el campo educativo y advierte sobre la intencionalidad de dicho proceso: subordinar la educación en calidad de apéndice de la economía. Por lo anterior, apela a considerar la práctica educativa como una relación dialéctica, holística, humanista, ética, donde tanto aprenden como enseñan quienes participan de ella, lo que permite plantear que la educación abre la esperanza a un mundo mejor.
\end{abstract}

Palabras claves: Educación, aprender, enseñar, ideología, Freire, globalización.

\begin{abstract}
Pedagogy of Autonomy" is a text in which Freire discusses how every educational endeavor is political and ideological, which is conditioned but not determined, and which goes beyond the mere acquisition of knowledge. It considers the knowledge required for teaching practices and highlights at least five cross-curricular themes: the dialectical relationship between learning and teaching, the importance of taking into account emotional aspects, the political implications, the fact that teaching is more than providing information, and educators' ethical commitment. It also argues that educational practices, as political endeavors, are deliberate and depend on the worldview (ideology) of educators. Such endeavors must entail the development of intentionality: the autonomy of the learner. Freire foresees the process of globalization and the impact of digital technologies on education and warns of the intent of such process: the subordination of education as an appendix to the world economy. Therefore, he recommends considering educational practices as holistic, dialectical, humanistic and ethical relationships in which both learners and teachers learn from one another which seems to indicate that education raises hope for a better world.
\end{abstract}

Keywords: Education, learning, teaching, ideology, Freire, globalization

1 Lic. Enseñanza de las Matemáticas Universidad de Costa Rica 1994. Maestro en Educción Instituto Tecnológico y de Estudios Superiores de Monterrey, México, 2012. Profesor Sede Guanacaste de la Universidad de Costa Rica. 


\section{Introducción}

Pedagogía de la autonomía de Paulo Freire: Saberes necesarios para la práctica educativa (1998) no es la obra más famosa de este pedagogo; pero es la más madura. En ella ofrece, de manera sucinta, toda su cosmovisión sobre la educación e incluye una crítica profunda sobre el perfil de la educación para el siglo XXI en el marco de la globalización.

El objetivo del texto es que el personal docente reflexione sobre los saberes requeridos que conlleva la práctica educativa, que comprenda su papel en calidad de agente de cambio social y que, independientemente de su opción política, tenga claro que su labor debe estar en procurar que sus estudiantes alcancen la autonomía para el aprendizaje, lo cual considera posible si desarrolla su labor en el marco de un modelo educativo dialógico, horizontal, donde se supriman el autoritarismo, el verticalismo y la educación bancaria, y tenga consciencia del carácter dialéctico de su relación con el alumnado. Además, quien ejerce la docencia debe saber que participa en el acto educativo con conocimiento de causa, por lo que es la persona más capacitada para darle sentido y dirección, solo así podrá contribuir a que sus discentes logren autonomía, criticidad, concienciación, libertad y ética, y sobre todo, capacidad de tomar decisiones y asumir sus consecuencias.

En razón de lo anterior, aún cuando el libro se centra en la acción de enseñanza por la parte docente, y trata sobre los saberes necesarios para la práctica educativa, el discurso de Freire se refiere a lo que el personal docente debe tomar en cuenta y poner en práctica para que sus estudiantes alcancen la autonomía para aprender por sí mismos y mismas. Es decir, la población meta de su visión pedagógica es el estudiantado, pero para llegar a estos grupos se debe pasar por sus docentes.

Aunado a lo anterior, Freire reafirma en esta obra que el acto educativo es un acto político y ético, y que a través suyo es posible lograr cambios en las personas que les permitan ser educadas y mejores. Lleno de esperanza y optimismo sobre esta posibilidad, invita a mirar una y otra vez el quehacer docente desde una perspectiva humanista y comprometida con el desarrollo del individuo, no con la economía. Lanza así un llamado a seguir creyendo en la educación presencial, cara a cara, frente a frente, donde docente y discente, más que compartir información y conocimientos, comparten sus vidas y proyectos, dialogan sobre sus visiones de mundo, crean espacios mutuos para enseñar y aprender; y es que solo cuando el personal docente acepta e implementa esta relación con sus estudiantes, puede establecer coherencia entre su discurso y su práctica, y con ello hacer la diferencia en el proceso de transformación de sus educandos y educandas para que logren su propia y permanente transformación.

Señala, además, que a pesar de la relación dialéctica entre enseñar y aprender, ha sido un error histórico asumir el acto educativo privilegiando la perspectiva de la enseñanza sobre el aprendizaje; propone, por ello, razones justificadas para conceptualizar que un cambio en la posición de los términos no es un simple juego de palabras, sino que responde a una lógica diferente, al considerar que enseñar debe ser concebido en razón del aprender y no en razón de la presentación de los contenidos que se asume deben ser aprendidos por el educando, lo que conlleva un cambio de paradigma tanto para docentes como para discentes. Esto significa que, por encima de la enseñanza, vista como presentación de la información, debe estar el cómo aprende el estudiantado, para así establecer cómo debe realizarse el acto de enseñanza a fin de potenciar al máximo el aprendizaje. 
En este cambio de paradigma se hace necesaria la incorporación de la investigación como parte inherente al acto educativo cuyo objetivo es lograr que el personal docente no se convierta en un instrumento para la transmisión de una visión fosilizada e ideologizada del mundo, aspecto propio de la globalización. La investigación debe promover el tomar consciencia de sus actos y sus implicaciones, elemento clave para desarrollar la labor educativa desde una posición ética, de compromiso, ya sea por la transformación o el sostenimiento del modelo de sociedad en el cual participa.

Freire establece que la labor docente requiere de al menos nueve saberes, los cuales son:

1. Seguridad, competencia profesional y generosidad.

2. Compromiso.

3. Comprensión de que la educación es una forma de intervención en el mundo.

4. Libertad y autoridad.

5. Una toma consciente de decisiones.

6. Saber escuchar.

7. Reconocer que la educación es ideológica.

8. Disponibilidad para el diálogo.

9. Querer bien al estudiantado.

Estos saberes no dependen de la posición ideológica o política de la persona docente, sino de su actitud ética porque: "son saberes demandados por la práctica educativa en sí misma, cualquiera que sea la opción política del educador o educadora" (Freire, 1998, p. 23).

Tales saberes parten de dos premisas:

a. No hay docentes sin discentes

b. Enseñar es mucho más que transmitir conocimientos.

Ello hace que propuesta educativa de Freire consista en una práctica educativa horizontal, donde docente y discente participan en igualdad de condiciones, pero con roles diferentes, por cuanto: "quien forma se forma y re-forma al formar y quien es formado se forma y forma al ser formado" (Freire, 1998, p. 25).

Con base en lo anterior, en el presente ensayo se reflexiona sobre las ideas educativas de Paulo Freire y se plantea la necesidad, importancia y, sobre todo, la pertinencia de tomarlas en cuenta en la actualidad, como mecanismo que contribuye a preservar el carácter antropológico de la educación, aspecto vital para enfrentar los modelos educativos surgidos en el marco de la globalización.

Para alcanzar los saberes necesarios para que la práctica educativa logre que el estudiantado alcance su autonomía, se requiere que el cuerpo docente tenga presente que esta se basa en cinco aspectos fundamentales, que aparecen a lo largo de toda la obra en calidad de ejes transversales; así, la práctica educativa: 
1. A pesar de su unidad dialéctica, debe partir del aprendizaje y no de la enseñanza.

2. Debe tomar en cuenta la importancia de los aspectos emocionales.

3. Es una práctica política.

4. Implica que enseñar es más que informar/adiestrar.

5. Es un compromiso ético.

\section{A pesar de su unidad dialéctica, la práctica educativa debe partir del aprendizaje y no de la enseñanza}

Desde la perspectiva de Freire, el fin primordial de la educación es la modificación de la conducta de la totalidad de sus participantes de dicho proceso, lo que lleva a la construcción de una relación formal entre docentes y discentes (término con que se refiere a los educandos) que está mediada por la información y la construcción de los conocimientos, pero considera que estos no se encuentran únicamente en los saberes establecidos en el currículo del sistema escolar, sino que también se encuentran en la realidad inmediata y concreta en la que participan; por eso, para Freire, en el proceso educativo pueden aportar tanto discentes como educadores y educadoras, por cuanto: "Quien enseña aprende al enseñar y quien aprende enseña al aprender" (Freire, 1998, p. 25).

Desde esta perspectiva, el proceso educativo implica un continuo intercambio de roles entre los sujetos enseñante y cognoscente, por lo que no se deben ver como categorías inamovibles, jerarquizadas y fosilizadas, sino en permanente movimiento donde el aprender y enseñar poseen una unidad dialéctica, merced a que la información y el conocimiento no son propiedad exclusiva de ninguno de ellos. Por lo anterior, la relación entre educador y educando incluye un proceso de retroalimentación constante por cuanto ambos enseñan y aprenden a la vez, tal y como lo plantea Verónica Millar al indicar: "cuando uno enseña también aprende ya que la educación es un proceso de retroalimentación constante por parte del educador como del educando" (Millar, 2007, p. 2).

Para los efectos correspondientes, en el presente ensayo, en términos generales, se entiende por enseñar a la presentación y transmisión de información que posibilita la construcción de conocimientos $y$, en contraparte, se considera como aprendizaje a la manifestación clara y distinta, por parte del educando, del dominio de un contenido de conocimiento específico, o el desarrollo de una destreza o habilidad, que previamente no podía manifestar. De esta manera, entre aprender y enseñar se desarrolla una relación dialéctica lo suficientemente compleja como para establecer que no tiene sentido hablar de enseñanza y aprendizaje como elementos aislados o separados, pero no significa que sea lo mismo plantear enseñanza-aprendizaje a aprendizaje-enseñanza.

Esta diferencia no es dada por un simple orden de palabras, porque en la perspectiva enseñanza-aprendizaje se prioriza la enseñanza sobre el aprendizaje, donde este se reduce a la adquisición de contenidos o destrezas en un área del saber, aspecto propio de los modelos educativos de enfoque transmisivo (Martínez, 2008), los cuales se basan en una buena planificación y una excelente didáctica, y hacen que el acto pedagógico gire en torno 
al quehacer del docente en calidad de transmisor de información, por lo que la labor de los educandos se caracteriza por ser el resultado del quehacer de este, aspecto que puede caer fácilmente en una educación de tipo bancario.

Frente a lo anterior, al plantear el proceso de aprendizaje-enseñanza se prioriza la construcción de conocimientos por parte del estudiantado, en el marco de un proceso dialógico y, por ende, social, tal y como lo sugiere Vigotsky, donde el aprendizaje marca el derrotero del acto pedagógico y, por tanto, el proceso de enseñanza queda subordinado a este (enfoque constructivista), lo que implica que el personal docente, previo a su desempeño como enseñante, debe procurar conocer cómo aprenden sus estudiantes, donde conocer sus estilos de aprendizaje se convierte en una necesidad vital (Nevot, 2001). De hecho, solo conociendo cómo aprende el estudiantado el esfuerzo de la enseñanza podría tener algún efecto positivo, ya que el papel docente es el de crear espacios y gestionar las condiciones que posibiliten organizar las situaciones de aprendizaje (Therer, 1998).

Comprendiendo lo anterior, Freire plantea: "Enseñar no se agota en el 'tratamiento' del objeto o del contenido, hecho superficialmente, sino que se extiende a la producción de las condiciones en que es posible aprender críticamente" (Freire, 1998, p. 27-28), porque solo cuando el personal docente conoce cómo aprenden sus estudiantes, la enseñanza puede impactar de manera positiva, lo que lleva a considerar que la práctica educativa no se mejora por repetición irreflexiva o la acumulación de información sobre cómo debe hacerse, sino como resultado de una reflexión-acción sobre el impacto del quehacer docente en el estudiantado; lo cual demanda investigar cómo ese impacto puede ser más significativo, aspecto que incluye saber escuchar a las demás personas y no partir de que el conocimiento que en determinado momento se llegó a poseer está a prueba del tiempo.

De esta manera se puede afirmar que el aprendizaje se ve influenciado por el dominio del personal docente sobre su disciplina; pero esto no es suficiente, porque intervienen además el ámbito de sus competencias, sus criterios y valores morales, la valoración que dé a las emociones, el modelo didáctico que implemente, pero particularmente su estilo de enseñanza (Amado, Brito y Pérez, 2007), el cual se manifiesta en la interacción que mantiene con su alumnado, debido a que el aprendizaje es personal y social a la vez, lo que significa que es coparticipado, por lo que no puede ser el resultado de una transmisión unidireccional. Freire conceptualizó esto con claridad al plantear: "no hay pensar sin entendimiento y el entendimiento, desde el punto de vista del pensar acertadamente, no es algo transferido sino coparticipado" (Freire, 1998, p. 38).

\section{La práctica educativa debe tomar en cuenta la importancia de los aspectos emocionales}

Las personas aprenden no tanto para una interacción social sino más bien en medio de una interacción social, lo cual hace que el aprendizaje sea condicionado, donde por más racional que parezca, siempre estará cargado de aspectos emocionales (Casassus, 2006). Esto sucede porque el aprendizaje depende de los intereses o necesidades de las personas, aspectos que están mediados por las emociones (García, 2012). Esto no pasa desapercibido para Freire, quien indica: "La práctica educativa es todo eso: afectividad, alegría, capacidad científica, 
dominio técnico al servicio del cambio o, lamentablemente, de la permanencia del hoy" (Freire, 1998, p. 75). Por eso, tomar en cuenta los aspectos emocionales durante el proceso de aprendizaje enseñanza es una necesidad, por cuanto estos aspectos son fundamentales para lograr el desarrollo integral del educando, ya que favorecen su capacidad de comunicación; aprende a resolver conflictos, tomar decisiones, planificar su vida; eleva su autoestima, incrementa su capacidad de flujo, y sobre todo, desarrolla una actitud positiva ante la vida (Bisquerra, 2005, citado por García 2012).

Cada docente debe tener claro que el aprendizaje constituye un constructo individual producto de una interacción social, afectado por las apreciaciones y valores que, individual y socialmente se le atribuyen, de manera tal que no hay aprendizajes fuera del espacio emocional (Pekrum, 2000, citado por Casassus, 2006), al punto de que las emociones son determinantes para facilitar u obstaculizar dichos aprendizajes, donde pueden llegar a ser más importantes que la información con que se trabaja:

A veces ni se imagina lo que puede llegar a representar en la vida de un alumno un simple gesto del profesor. Lo que puede valer un gesto aparentemente insignificante como fuerza formadora o como contribución a la formación del educando mismo. (Freire, 1998, p. 43)

Así las cosas, la educación debe conjugar el aprender conocimientos específicos de las diferentes áreas del saber humano con el desarrollo de los aspectos emocionales: "Siendo una práctica estrictamente humana, jamás pude entender la educación como una experiencia fría, sin alma, en la cual los sentimientos y las emociones, los deseos, los sueños, debieran ser reprimidos por una especie de dictadura racionalista" (Freire, 1998, p. 139).

Por lo anterior, el arte de enseñar demanda del personal docente el aceptar y saber manejar la parte emocional que le es inherente, debe reconocerla en todo momento e incorporarla por cuanto:

No es cierto, sobre todo desde el punto de vista democrático, que seré mejor profesor cuanto más severo, más frío, más distante e "incoloro" me ponga en mis relaciones con los alumnos, en el trato con los objetos cognoscibles que debo enseñar. La afectividad no está excluida de la cognoscibilidad. (Freire, 1998, p. 135)

Y es que la construcción del conocimiento depende de las experiencias, valores, intereses, ignorancias, capacidad de articular conocimientos previos, proyección en la vida, sentimientos. Nadie aprende lo que no quiere aprender por excelente que sea la enseñanza que se le brinde.

\section{La práctica educativa es una práctica política}

Según Freire, la educación debe partir de la realidad, lo que implica aceptar el reto de su transformación en razón del bien común y no de intereses egoístas. Pero la "realidad" no es igual para todos los individuos, depende de la visión de mundo que cada quien posea: "Quien observa lo hace desde un cierto punto de vista" (Freire, 1998, p. 16), e interpreta "el punto 
de vista" como la visión política que cada quien tiene del mundo, lo que hace que la educación tenga necesariamente que ser política: "La educación no se vuelve política por causa de la decisión de este o de aquel educador. Ella es política" (Freire, 1998, p. 106), y lo es porque en la interacción social se conjugan los diferentes puntos de vista de diferentes actores.

De esta manera Freire consideró que, a través de la educación y la política, las personas se insertan en el mundo para su transformación o mantenimiento, y a la vez son sujetos de esa transformación o mantenimiento, en razón de procurar mejorar la calidad de sus vidas. Debido a lo anterior, considera la educación y la política como espacios imprescindibles dentro de la convivencia humana, por lo que asegura: "Para que la educación no fuera una forma política de intervención en el mundo sería imprescindible que ella se diera en un mundo que no fuera humano" (Freire, 1998, p. 107). Freire establece así una diferencia entre política e ideología, por cuanto la política tiene que ver con la interacción social, mientras la ideología es el mecanismo que utilizan los grupos de poder para ocultar la realidad: "Es que la ideología tiene que ver directamente con el encubrimiento de la verdad de los hechos, con el uso del lenguaje para ofuscar u opacar la realidad al mismo tiempo que nos vuelve "miopes" (Freire, 1998, p. 120). De esta manera, la razón de ser de la ideología es dar una versión de una visión de mundo que tiende a rechazar la perspectiva de los demás y con ello ocultar la realidad; por eso Freire apela a romper con aquellas posiciones ideologizadas que imposibilitan apreciar los puntos de vista ajenos, y que dificultan y hasta impiden a las personas el poder comunicarse y consensuar.

Freire no oculta que toda acción humana, en tanto acción política, está influida por aspectos ideológicos, pero indica que tales aspectos no deben estar por encima de la interacción social y el bien común; esto lo lleva a considerar que no es posible aducir una visión neutra o apolítica de la educación, porque: "Para que la educación fuera neutral sería preciso que no hubiera ninguna discordancia entre las personas con relación a los modos de vida individual y social" (Freire, 1998, p. 106), por lo que asumir una supuesta posición neutra es imposible y:

Desde ese punto de vista, que es reaccionario, el espacio pedagógico, neutro por excelencia, es aquel en el que se adiestran los alumnos para prácticas apolíticas, como si la manera humana de estar en el mundo fuera o pudiera ser una manera neutra. (Freire, 1998, p. 94)

De esta manera, Freire reclama así a aquellos y aquellas docentes que aducen adoptar una posición "neutra" en términos político-ideológicos, porque esta posición es la más ideologizada de todas; y dado que la ética y la honestidad van de la mano, demanda al personal docente ser consecuente entre su decir y su hacer, lo que conlleva plantear abiertamente qué postura asume en términos de visión del mundo. Para Freire el que las personas tengan posiciones político-ideológicas diferentes no debe ser un obstáculo para buscar puntos de común acuerdo, más bien el problema está en negar que se tiene determinada posición, porque esto contribuye a fortalecer el espejismo ideológico que encubre el esfuerzo enajenante de una educación en función del modelo económico y que está en razón de suprimir la condición de ser humano del educando para "domesticarlo", a través de: "el poder invisible de la domesticación enajenante que alcanza una eficacia extraordinaria en lo que vengo llamando 'burocratización de la mente"' (Freire, 1998, p. 109). 
Es decir, aducir una posición neutra no es más que actuar de manera farisaica, porque: "¿Qué otra cosa es mi neutralidad sino una manera tal vez cómoda, pero hipócrita, de esconder mi opción o mi miedo de denunciar la injusticia?" (Freire, 1998, p. 107).

A partir de asumir de manera abierta y franca una postura política e ideológica, Freire cree e invita a creer en la humanidad por excelencia, en el ser humano como elemento transformador de su realidad y de su entorno, donde la educación, como actividad humana que se desarrolla en contextos sociales e históricos definidos, hace que sus participantes estén condicionados pero no determinados. Por ello, cada docente debe decidir si trabaja, o no, de manera coherente, en el imaginario de un mejor mundo posible, por cuanto la acción docente conlleva una intervención en el mundo, cuya finalidad es la de transmitir al educando una visión particular y específica de la realidad como parte de su acción política, la cual puede implicar una de dos cosas: consolidar, mantener y preservar el statu quo existente, o trabajar en su transformación, lo que muchas veces conlleva acciones contestatarias. De ahí que Freire afirme que la educación es una: "Intervención que más allá del conocimiento de los contenidos bien o mal enseñados y/o [sic] aprendidos implica tanto el esfuerzo de reproducción de la ideología dominante como su desenmascaramiento" (Freire, 1998, p. 95).

Para él, el personal docente que cree en la educación debe verse a sí mismo como un medio para la transmisión de cultura, capaz de influir en la construcción de la personalidad del estudiantado; por esto su papel va más allá de cumplir con la presentación de una serie de contenidos de un área del saber, y está ligado a la construcción de la personalidad de su alumnado: "lo fundamental en el aprendizaje del contenido es la construcción de la responsabilidad de la libertad que se asume" (Freire, 1998, p. 91). Para el logro de esto, el personal docente no puede presentarse ante sus estudiantes como si fuera un ser "superior", discriminador y ajeno a la realidad que viven, de hecho, si en verdad la intención que anima al personal docente es democrática y solidaria, su intervención en el mundo demanda un rechazo al autoritarismo, a hablar a las otras personas desde arriba, como si fuera el portador de la verdad que hay que transmitir cerrando los oídos a lo que los demás individuos tienen que decir, negando el escucharles, porque según Freire, solo cuando se aprende a escuchar a los demás es que se aprende a hablar con ellos y ellas.

De ahí que es clave la percepción docente sobre el concepto de autoridad, pues de una u otra manera la ejerce. Si la asume desde una postura vertical, jerárquica o (como la define el mismo Freire), mandonista, esto: "no supone ninguna creatividad en el educando. No forma parte de su forma de ser (Freire, 1998, p. 89); pero existe otra postura, donde, sin perder el papel de autoridad, pueda actuar de una manera más "horizontal", capaz de estimular la libertad y combatir el libertinaje, de dar orden y evitar el caos, sin que ello implique pasar por encima de la libertad del estudiantado. Así:

La autoridad coherentemente democrática, que se funda en la certeza de la importancia, ya sea de sí misma, ya sea de la libertad de los educandos para la construcción de un clima de auténtica disciplina, nunca minimiza la libertad. Por el contrario, le apuesta a ella. Se empeña en desafiarla siempre y siempre; nunca ve, en la rebeldía de la libertad, una señal de deterioro del orden. La autoridad coherentemente democrática está convencida de que la verdadera disciplina no existe en la inercia, en el silencio de los 
silenciados, sino en el alboroto de los inquietos, en la duda que instiga, en la esperanza que despierta. (Freire, 1998, p. 89)

De esta manera, Freire propone que las relaciones entre estudiantes y docentes se definen desde la perspectiva de lograr consensos entre las posturas política e ideológica de ambos, dado que tanto educandos como docentes actúan sobre la base de sus criterios políticoideológicos y pueden presentarse conflictos en el orden de la interpretación de los hechos. El personal docente no debe temer este tipo de conflictos y, por el contrario, si le mueve un espíritu democrático debe estimularles en un marco de respeto, orden, convivencia y disciplina para evitar que estudiantes que no logran interpretar ese espíritu, caigan en el libertinaje.

Por otra parte, en los últimos 10 años, y posterior a la muerte de Freire, la humanidad entró en un proceso de globalización de la economía que ha afectado el orden mundial y ha transformado las relaciones entre las personas, los pueblos y las naciones, abarcando todo el quehacer humano; la educación no escapa a ello. En esta nueva era de la humanidad, la economía ha pasado a ser abiertamente el eje central de la actividad humana, lo que ha llevado a muchos a considerar que la educación debe estar en función de esta, y en razón de ello han propuesto diferentes modelos y estrategias educativas. Destacan aquellas que plantean a la información y su manipulación como ejes centrales del modelo y el proceso educativo, donde su procesamiento define qué debe entenderse como conocimiento y saber, en razón de constituir un insumo productivo, como aspecto clave para favorecer y lograr la competitividad empresarial (Hopenhayn, 1987), lo que ha llevado a que el conocimiento sea considerado como la principal fuerza de producción (Lampert, 2008) en la actualidad.

Paralelo a la globalización surgió la denominada sociedad del conocimiento y con ella el boom del uso de las tecnologías digitales (TD) como recursos educativos más que como apoyos metodológicos, las cuales son consideradas como los elementos claves para la generación, procesamiento y transmisión de información y constituyen: "un factor esencial de poder y productividad, en consecuencia, resulta cada vez más necesario educar para la sociedad de la información desde las etapas más tempranas de la vida escolar" (Escontrela y Stojanovic, 2004, A modo de conclusión, Párr. 1). Este criterio es reflejo del perfil de una educación al servicio de la economía, ya sea a través de la producción de bienes materiales de vida o de la venta de servicios, por encima del desarrollo integral de la persona, de su realización personal, es decir, ponen a la economía por encima del desarrollo humano.

Así, mediante el uso de las tecnologías digitales, se han propuesto modelos educativos cuya finalidad es la de condicionar y adoctrinar desde las etapas más tempranas de la vida, al estudiantado con la finalidad de poder "atarlos" a un modelo de producción de manera acrítica, suprimiendo su carácter humano y convirtiendo a la persona en una especie de anexo de las máquinas (Carr, 2011). Esto fue pre-visto por Freire, de ahí que en Pedagogía de la autonomía hace una crítica razonada sobre la globalización como la máxima expresión de la sociedad capitalista y cómo esta pretende convertir al sujeto en objeto de mercado y alerta sobre lo anterior al indicar:

Desde el punto de vista de tal ideología, solo hay una salida para la práctica educativa: adaptar al educando a esta realidad que no puede ser alterada. Lo que se necesita, por 
eso mismo, es el adiestramiento técnico indispensable para la adaptación del educando, para su sobrevivencia. El libro con que vuelvo a los lectores es un decisivo no a esta ideología que nos niega y nos humilla como gente. (Freire, 1998, p. 21)

De esta manera, Freire denuncia los entonces incipientes esfuerzos por ajustar al estudiantado a la económica globalizada y al libre comercio cuando afirma: "La libertad del comercio no puede estar por encima de la libertad del ser humano" (Freire, 1998, p. 124), a lo que agrega: "Para mí es una inmoralidad que a los intereses radicalmente humanos se sobrepongan, como se viene haciendo, los intereses del mercado" (Freire, 1998, p. 96).

El riesgo de convertir la educación en un proceso de enajenación y domesticación se ha incrementado en la sociedad actual en la medida en que las TD irrumpen en el modelo educativo de manera acrítica y sin control, como si fueran la panacea de los problemas de la educación (García, 2014). Esta irrupción se da en razón de su capacidad para aportar información prácticamente sin límite, sin control alguno, sin criterios éticos, de manera tal que dejan al total albedrío del educando el decidir cuál transforma en conocimiento, lo que revela que las TD aún cuando "enseñan" (realmente muestran o aportan información) no educan, y no educan porque no forman: "y no forman porque no pretenden promover virtudes, aunque tengan sin duda una notable influencia en la conducta de las personas" (Altarejos y Naval, 2004, p. 197). Es decir, las TD no resuelven los problemas epistemológicos, didácticos ni éticos que puedan tener tanto docentes como estudiantes con respecto al proceso de aprendizaje-enseñanza.

A pesar de ello, la sociedad capitalista actual requiere de modelos educativos que potencien en cada individuo el desarrollo al máximo de sus habilidades y destrezas, estimulen la disposición para aprender y generen un capital cultural que potencie la capacidad productiva. En esta dirección, la Organización para la Cooperación y el Desarrollo Económico (OCDE) ha planteado el enfoque basado en competencias (EBC) como una alternativa a ser tomada en cuenta de cara al siglo XXI (OCDE, 2010). Este modelo, basado en el manejo de la información, fomenta la idea de que esta es poder, está compuesto por la siguiente trilogía: el capital humano, el sistema de producción y un aparato de información y conocimiento, donde estos dos últimos elementos constituyen sus fundamentos (Picardo, 2002). Esto contribuye a generar la idea de que tener acceso a la información (en particular por medio de las TD) es una actividad vital para el surgimiento del "ser humano informado", capaz de convertir la fluctuante, y siempre cambiante, información en conocimiento que posibilite una toma de decisiones lo más económica posible, y que a la vez produzca las mayores ganancias posibles al potenciarse la capacidad productiva (García, 2014).

Y es que aun cuando algunos de los modelos educativos propuestos para la economía globalizada, como en el caso del EBC, se aduce el trabajo colectivo o en equipo, la tendencia manifiesta, en razón del uso de las TD, es el individualismo (García, 2014), donde el manejo de la información determina lo que es bueno, correcto o conveniente en razón del ajuste del educando para lograr que ocupe un puesto específico en el modelo económico y particularmente en la esfera productiva, lo que convierte el capital intelectual en un nuevo activo para la generación de riqueza (Gómez, 2004, citado por García, 2014). Esto, desde la perspectiva de Freire, conduce a considerar que: "lo válido hoy es el 'pragmatismo' pedagógico, es el adiestramiento técnicocientífico del educando y no su formación, de la cual no se habla más” (Freire, 1998, p. 121). 
A pesar de ello, Freire mantiene su confianza de que un mundo mejor es posible por cuanto: "El mundo no es. El mundo está siendo" (Freire, 1998, p. 75), es decir, más allá del perfil que define la globalización para el modelo educativo, es posible hacer las cosas de manera diferente, por lo que se hace necesario: "establecer una dialéctica entre la denuncia de la situación deshumanizante y el anuncio de su superación, que es en el fondo nuestro sueño" (Freire, 1998, p. 77).

Así las cosas, el personal docente debe decidir si su acto educativo se orienta hacia contribuir a que sus estudiantes logren un pensamiento crítico y reflexivo, capaz de ver en el mundo oportunidades para hacer de él un lugar mejor y ser sujetos de su propia historia, o si contribuye a que los mismos se conviertan en objetos ligados al aparato productivo merced al adiestramiento que propone la globalización, y dado que la educación no es neutra, o educa o domestica, por cuanto, si educar tiene que ver con "formar" y: "formar es mucho más que simplemente adiestrar al educando en el desempeño de destrezas" (Freire, 2004, p. 5), debe preservarse la esperanza de que el acto pedagógico se pueda orientar hacia el ser humano y no hacia el aparato productivo.

\section{Enseñar es más que informar/adiestrar}

Como se comprenderá, Freire no llegó a vivir la sociedad del conocimiento que ha surgido en el marco de la globalización, pero perfiló cómo podría ser un modelo educativo relacionado con esta nueva realidad; por ello propuso romper con la idea de que la educación es un proceso vertical, a través del cual las generaciones más "viejas" transmiten unilateralmente la cultura y la ideología, por el contrario, para él:

En las condiciones del verdadero aprendizaje los educandos se van transformando en sujetos reales de la construcción y la reconstrucción del saber enseñado, al lado del educador, igualmente sujeto del proceso. Solo así podemos hablar realmente de saber enseñado en que el objeto enseñado es aprehendido en su razón de ser y, por lo tanto, aprehendido por los educandos. (Freire, 1998, 28)

Esto tiene que ser así, porque el aprendizaje tiene que ver con la parte experiencial de los individuos, de ahí que el rol del docente debe orientarse a construir espacios que favorezcan en el estudiantado el desarrollo de la capacidad de asumir responsablemente su libertad y que pueda ser autónomo para participar en su transformación.

Cabe, entonces, la pregunta: ¿Qué es lo que permite a las personas el poder aprender? Para Freire, es el carácter inconcluso del ser humano, su condición de ser inacabado, aspectos que permiten perseguir el ser más completos, tanto de manera individual como colectiva. Pero esto solo es posible, si la persona acepta esas dos condiciones, por cuanto: "la inconclusión que se reconoce a sí misma implica necesariamente la inserción del sujeto inacabado en un permanente proceso social de búsqueda" (Freire, 1998, p. 54).

Es decir, el carácter inconcluso que caracteriza a los seres humanos es precisamente la clave para poder aprender y define el quehacer de la labor docente, la cual demanda un esfuerzo permanente por mejorar, lo que obliga la incorporación de la investigación como una 
acción cotidiana, inherente a tal labor. En razón de lo anterior, Freire propone partir de la cotidianeidad como el elemento educativo por excelencia, de forma que el acto pedagógico se contextualice de manera permanente y así contribuya a comprender y transformar la realidad de los participantes. Por ello Freire pregunta al lector: “¿Por qué no establecer una 'intimidad' necesaria entre los saberes curriculares fundamentales para los alumnos y la experiencia social que ellos tienen como individuos? "(Freire, 1998. p.32), o lo que es igual: ¿es posible realizar una mezcla entre lo que el modelo educativo persigue y la realidad del estudiantado?

Para Freire la respuesta es afirmativa, pero para lograr esto el personal docente debe aceptar, con humildad, que no tiene el conocimiento completo, que debe investigar día con día cómo adquirirlo, reflexionar sobre el conocimiento adquirido para enriquecerlo, contextualizarlo siempre para lograr darle sentido personal y compartir ese sentido con sus estudiantes; solo de esta manera el conocimiento no será un cliché, una pegatina que se puede colocar en la frente de las personas para que "jueguen” a poseerlos, solo así deja de estar fosilizado, porque el docente es capaz de revitalizarlo al plantear su presencia en la vida cotidiana de los educandos.

Para lograr lo anterior, el educador o la educadora deben investigar y conocer las condiciones del contexto y, por ende, de sus discentes para la realización del acto educativo, lo que le permitirá relacionar el contenido específico que enseña con las distintas realidades que podrían encontrarse en las aulas, aportadas por cada estudiante con quien trabaja, de ahí que en todo acto educativo enseñar e investigar están íntimamente relacionados, por lo que no es coherente ni consecuente el imaginar que uno solo de estos elementos pueda aparecer como un hecho aislado:

No hay enseñanza sin investigación ni investigación sin enseñanza. Esos quehaceres se encuentran uno en el cuerpo del otro. Mientras enseño continúo buscando, indagando. Enseño porque busco, porque indagué, porque indago y me indago. Investigo para comprobar, comprobando intervengo, interviniendo educo y me educo. (Freire, 1998. p. 30-32)

Por lo tanto, enseñar-investigar están en razón de potenciar en el estudiantado el aprender, de ahí que aprender-enseñar-investigar se constituye en una unidad que demanda de cada docente una actitud de reflexión crítica constante, continua, permanente y cotidiana, sobre su práctica docente, con el ánimo de mejorarla. Inherente a esta unidad está el que debe incluirse dentro de la investigación, es decir, debe ser sujeto de su propia investigación para poder dar respuesta coherente a la siguiente pregunta: ¿Para qué trabaja en docencia? La respuesta a esto puede ir desde mejorar los procesos de "adiestramiento", de ajuste del grupo estudiantil al modo de producción y con ello lograr insertarlo en la sociedad globalizada para que pueda sobrevivir a esta, o para generar un individuo independiente, autónomo, consciente y crítico.

La unidad aprender- enseñar- investigar es una muestra evidente que enseñar es más que mostrar conocimientos y tiene que ver, principalmente, con el cómo y no tanto con el qué, de los contenidos que se enseñan. Debe tomarse en cuenta que la información puede ser presentada de múltiples formas, y particularmente en la sociedad del conocimiento, a través de las tecnologías digitales, pero el presentar información no significa que se construya conocimiento, aspecto que afecta la interacción entre estudiantes y con estudiantes. Por otra parte, la información 
o el conocimiento no se adquieren únicamente por el placer de poseerlos, de hecho la mayoría de las veces se obtiene información y se construye conocimiento por la necesidad de contar con recursos que contribuyan a desarrollar determinadas tareas o acciones que, inevitablemente, se dan en entornos sociales, por lo que su adquisición no puede ignorar el contexto.

De esta manera, la información y el conocimiento a ser aprendido-construidos por el estudiantado, enfrentan al personal docente desde las perspectivas profesional (manejo de tales contenidos), ética y moral (responsabilidad social en el manejo de los contenidos), metodológica (cómo lograr que los educandos construyan contenidos significativos para ellos en el marco del contexto social que viven), relaciones humanas (respeto mutuo), aceptación de la autoridad (rechazo al autoritarismo y verticalización de la relación docente-discente, que no significa ni libertinaje ni indiferencia), ideológica (tomar una posición clara y coherente, respetar la de las demás personas, negar los absolutismos) y política (aceptar el carácter social de las personas, por cuanto el conocimiento es social y solo en la sociedad tiene sentido).

Entonces, no basta aportar al estudiantado la información como elemento único para la construcción del conocimiento, ya que este depende de múltiples factores, y se desarrolla en un entorno que debe considerar el carácter holístico de su aprendizaje. Así las cosas, el conocimiento debe ser el producto de la interacción de las personas que participan en el acto educativo y surgir del entorno, es decir, ser producto de la contextualización que quienes participan del acto educativo hagan de este. Pero, contextualizar demanda la capacidad para "problematizar el mañana", problematizar para construir una cosmovisión que permita tanto a docente como a discente, ser en el mundo y con el mundo, ya sea modificándolo o perpetuándolo.

De esta manera, la contextualización no se refiere únicamente al detalle de las condiciones materiales, sociales y económicas que enfrentan los actores del acto educativo en un momento determinado; lo cual es necesario pero no suficiente, sino más bien significa un posicionamiento en la historia de los individuos, darle significatividad al entorno, reconocer el acervo cultural del que tanto docente como discente son partícipes y herederos y tener claro cómo el contexto se transforma en el tiempo, en tanto se transforman tales actores, por lo que el personal docente no debe hacer lo que hacía y como lo hacía hace 20 o 10 o 5 años y, en algunos aspectos, ni siquiera como lo hacía un año atrás, porque esto sería incoherente y antiético.

De ahí la importancia de que todo proceso de enseñanza sea iniciado con un diagnóstico del entorno de donde se realizará la acción educativa, que abarque la situación de sus participantes y sus perspectivas, objetivos del currículo abierto y oculto, así como los objetivos de discentes y docentes para poder determinar posibles causas y efectos relacionados con el proceso educativo, tanto externos como internos. Solo así será posible determinar y propiciar mecanismos que faciliten los aprendizajes y las correspondientes modificaciones de la conducta.

En el esfuerzo por interpretar a Freire, es plausible considerar que en su cosmovisión del acto pedagógico concurren tres elementos claves: el pre-texto que aporta los pretextos del acto; el texto del acto, que se refiere a la intencionalidad de este, y el con-texto que se desarrolla en un contexto específico. Estos tres aspectos se dan dentro de una unidad dialéctica, por lo que su separación y comprensión se realiza solo por razones epistemológicas y gnoseológicas.

El pre-texto del acto educativo está conformado fundamentalmente por los contenidos a ser comunicados para la construcción del conocimiento, los cuales muchas veces son 
previamente conocidos por el personal docente; sin embargo, constituyen el pretexto del acto en sí, en el sentido de que los conocimientos solo son los motivos o excusas que se alegan para favorecer el acto de la comunicación necesaria para concretar el texto.

El texto del acto educativo es realmente su "corazón", y se corresponde con la intencionalidad, ya sea de la política educativa que se persigue socialmente transmitir a través del modelo educativo; o del profesorado (en su afán de compartir su visión del mundo con sus estudiantes). Esta intencionalidad depende de los criterios políticos e ideológicos que procure inculcar la política educativa, o bien que posea cada docente, ya que tal intencionalidad, o texto del acto educativo, responde a la creencia de que es posible trasladar, o al menos mostrar, a los educandos y educandas una visión de mundo, con la idea de que esto pueda contribuir a que construyan su propia visión. De esta manera, el texto del acto educativo se da en dos instancias, la definida en la política educativa del Estado y que se manifiesta en los programas de estudios, los cuales son definidos por las autoridades educativas y se plasman en el currículo abierto, pero sobre todo en el oculto, y la que se refiere a la intencionalidad específica del docente, qué lo hace actuar de una manera específica y no de otra, la cual muchas veces va en contra de las directrices institucionales o definidas por la política educativa vigente y que supuestamente debe implementar.

Adicionalmente, el texto del acto educativo puede darse en dos escenarios diferentes, uno en que coinciden las intencionalidades del programa y docente, lo que llevaría al reforzamiento del statu quo (sostenimiento del modelo social, político y económico de la sociedad en la cual se participa), y otro en que no coinciden, lo que podría implicar acciones contestatarias, por la parte docente, en procura de una transformación del individuo y con ello de la sociedad. Ante estas situaciones, Freire plantea la necesidad de desarrollar una actitud respetuosa, pero de lucha permanente, que si se sabe manejar, puede llegar a contribuir al enriquecimiento tanto del estudiantado como del educador y educadora, así como de la sociedad en su conjunto.

Por último, el con-texto consiste en el espacio de interacción social que favorece la construcción del conocimiento en un contexto específico, es el escenario donde entran en juego todos los componentes emocionales, sentimentales y cognitivos requeridos para la construcción del conocimiento. El con-texto conlleva la comunicabilidad que el acto educativo demanda y que se materializa en la construcción social del conocimiento históricamente acumulado, constituye la base de la construcción de nuevos posibles conocimientos.

Por lo anterior, el rol docente no tiene que ver con sus buenas intenciones, de hecho estas no definen los comportamientos reales, e incluso muchas veces ocultan sutilmente las manipulaciones ideológicas de las que pueden ser objeto tanto estudiante como docente. Por ejemplo, las "buenas intenciones" pueden llevar al personal docente a considerar que sabe "qué es lo bueno para los educandos", lo cual no es más que uno de los elementos que más finamente (por su carácter ideológico en términos de encubrimiento) han desarrollado las clases dominantes y deviene del considerar que las nuevas generaciones están en manos de las precedentes para su formación, instrucción o adoctrinamiento. Frente a esto, Freire propone: "una de las tareas fundamentales del educador progresista es, sensible a la lectura y relectura del grupo, provocar a éste y estimular la generación de la nueva forma de comprensión del contexto" (Freire, 1998, p. 80). 
Esto obliga al docente consciente a conceptualizar y comprender, de manera continua y permanente, el pre-texto, el texto y el con-texto en donde realizar su labor docente, y significa que no hay otra posibilidad que el actuar desde la ética definida por Freire, la que demanda el deber de ser coherente entre lo que dice y lo que hace: "De allí que, una de mis preocupaciones centrales deba ser la de buscar la aproximación cada vez mayor entre lo que digo y lo que hago, entre lo que parezco y lo que realmente estoy siendo" (Freire,1998, p. 92-94).

\section{La práctica educativa es un compromiso ético}

Para Freire, ética significa poseer coherencia entre lo que se piensa, se dice y se hace, respetando los criterios que presentan los demás seres. Esto significa que desde la ética de Freire, nadie es poseedor de la verdad, porque esta es una construcción colectiva que demanda el respeto de los criterios que son diferentes a los que la persona posee. La ética incluye ser consecuente con la posición política que se asuma, actuar con base en ella y respetar a quienes tengan otra posición, aunque sea totalmente opuesta: "Por más que una persona me desagrade yo no puedo menospreciarla con un discurso en el cual, creído de mí mismo, decreto su incompetencia absoluta" (Freire, 1998, p. 49).

Por lo anterior, es imposible separar la ética de la acción docente: "Tan importante como la enseñanza de los contenidos es mi coherencia en el salón de clase. La coherencia entre lo que digo, lo que escribo y lo que hago" (Freire, 1998, p. 100), de hecho saber esto y actuar en concordancia con ello es un saber indispensable para la práctica docente: "El saber que es imposible desligar la enseñanza de los contenidos de la formación ética de los educandos" (Freire, 1998, p. 91).

$\mathrm{Y}$ dado que el acto educativo es un acto social, y por ende político, demanda del docente que actúe de manera consciente y consecuente por cuanto: "La enseñanza de los contenidos implica el testimonio ético del profesor" (Freire, 2004. p. 30). De esta manera, el personal docente valida sus palabras con su ejemplo, es decir, que lo que hace habla por él, y no lo que dice que se debe hacer:

El profesor que realmente enseña, es decir, que trabaja los contenidos en el marco del rigor del pensar acertado, niega, por falsa, la fórmula farisaica, del 'haga lo que mando y no lo que hago'. Quien piensa acertadamente está cansado de saber que las palabras a las que falta corporeidad del ejemplo poco o nada valen. (Freire, 1998, p. 35)

Por eso, en la práctica educativa es tan malo desconocer la disciplina que se enseña, cómo se debe enseñar y el cómo y por qué aprenden el estudiantado (Bonilla, 1998), porque estos desconocimientos rompen la coherencia entre el decir y el hacer docente, y puede llevarle a asumir posiciones que van del autoritarismo y el mesianismo, hasta la desidia e indiferencia, de hecho la naturaleza ética de la educación demanda estar en permanente revisión de enseñar-aprender-investigar para mejorarlos.

Considerando el carácter inconcluso de las personas, Freire propone que siempre hay algo viejo que se puede hacer mejor y algo nuevo que se puede aprender, lo cual implica un 
acto de humildad que permite a aprendices llegar a ser expertos y a expertos mantener una condición de aprendiz permanente, aspectos que constituyen la base del buen juicio, la flexibilidad y el enriquecimiento personal constante. Solo así se logra el desarrollo de las capacidades intelectuales, valores morales y estéticos, la afectividad y la sensibilidad ante los fenómenos naturales y sociales (Fraboni y Pinto, 2006).

De ahí que sea un compromiso ético del profesorado procurar, permanentemente, actualizarse en el manejo del área del saber que imparte, enriquecer todo lo relativo a la metodología, la cual cambia según el currículo y el contexto, identificar los objetivos del currículo abierto y, especialmente del oculto. Por ello, el personal docente debe re-actualizarse y re-pensarse permanentemente, porque no es lo mismo un año de experiencia repetido 20 veces que 20 años de experiencia: "El profesor que no lleve en serio su formación, que no estudie, que no se esfuerce por estar a la altura de su tarea no tiene fuerza moral para coordinar las actividades de clase" (Freire, 1998, p. 88).

Si se parte de Freire, se comprenderá que cuando quien ejerce la docencia reconoce su carácter inconcluso como persona, es capaz de superar el temor a cometer errores en su práctica educativa, puede aceptar que esto puede suceder (de hecho sucede) y, por lo tanto, debe tener la humildad para reconocerlo para poder corregirlo, para que su práctica educativa pueda ser cada vez mejor: "El error en verdad no es tener un cierto punto de vista, sino hacerlo absoluto y desconocer que aún desde el acierto de su punto de vista es posible que la razón ética no esté siempre con él" (Freire, 1998, p. 16).

De esta manera, según Freire, no hay pretexto que justifique el ser mal docente y deja en claro que la educación es un compromiso, por eso se debe procurar siempre hacerlo cada vez mejor a pesar de las limitaciones y los condicionantes. Por último, la ética no se puede enseñar como un contenido específico, porque ella constituye uno de los ejes transversales de la coherencia entre el pre-texto, el pretexto, el texto, y el con-texto junto con el contexto, la ética se vive en la medida que estos cinco elementos se articulen coherentemente.

\section{A modo de conclusión: El compromiso y la esperanza}

A través de Pedagogía de la autonomía: Saberes necesarios para la práctica educativa, Freire invita a asumir un compromiso con la educación desde una perspectiva personal, social e histórica; compromiso que demanda el convencimiento de que cada hombre y mujer que existen pueden cambiar el entorno, pueden transformar su realidad, por lo que estos no se deben aceptar como cosas dadas e inmutables, sino como posibilidades, producto de las relaciones humanas, en un contexto político e ideológico históricamente definido, donde la educación es y será un recurso antropológico que posibilita el transmitir una visión del mundo, la cual puede estar en función de consolidar, mantener y preservar un modelo específico de sociedad; o, por el contrario, presentar acciones contestatarias que procuren su transformación; donde enseñar constituye un acto deliberado, de carácter político e ideológico que va más allá de la transmisión de información, ya que quien enseña puede ser consciente o no de ello.

Para Freire, el proceso educativo se basa en la relación docente-discente, así como información-conocimiento. Estas relaciones son dialógicas y dialécticas, verticales y 
horizontales, muestran autoridad y rechazan el caos, permiten y estimulan un permanente cambio de roles entre los sujetos enseñante y cognoscente, y dependen de los objetivos que cada uno pretenda, dado que los conocimientos o información no son propiedad exclusiva de uno solo de los actores, sino de ambos en razón de sus experiencias, lo que implica un proceso de retroalimentación constante, porque ambos enseñan y aprenden a la vez, como parte de un proceso activo. Así, la tarea docente va más allá de la presentación de información, por cuanto enseñar incluye formas de pensar, decir y actuar de manera coherente en razón de posibilitar que el estudiantado se vea involucrado en la construcción y reconstrucción de los saberes de manera consciente y crítica.

Desde la perspectiva de Freire, la acción docente no tiene que ver con las buenas intenciones, porque esto podría orientarse hacia el "mandonismo" como expresión de autoritarismo, y hacer caer al personal docente en el espejismo de verse a sí mismo como la fuente del conocimiento, o el único guía autorizado para emitir criterio, como si fuera un mesías (sé lo que es bueno para los educandos), lo cual iría en contra de un acto educativo dialógico y dialéctico. Según Freire, evitar lo anterior es parte de la responsabilidad ética, por cuanto la enseñanza de contenidos no es más que un pretexto para estimular en el estudiantado el aprendizaje autónomo que le permita ejercer su libertad, la cual solo existe con la presencia de otras personas.

Para que el acto educativo tenga sentido, el personal docente debe tomar en cuenta, en primera instancia, la contextualización de los sujetos participantes. Esta contextualización refleja la capacidad de los participantes del acto educativo para "problematizar el mañana", demanda construir una cosmovisión que permita tanto a docente como a discente, ser en el mundo y con el mundo, ya sea para perpetuarlo o modificarlo. De ahí la conveniencia de que todo proceso de aprendizaje-enseñanza se inicie con un diagnóstico del contexto de donde se realizará la acción educativa, la situación de sus participantes, sus perspectivas, objetivos del currículo abierto y oculto; para poder determinar causas y efectos, tanto externos como internos, al proceso educativo. Solo así será posible determinar y propiciar mecanismos que faciliten los aprendizajes, es decir, modificar la conducta.

Freire acusa a la globalización de actuar como la máxima expresión de la sociedad capitalista, la cual pretende convertir al estudiantado en objeto dentro del modelo de producción en una economía basada en el mercado, incluso negándole su dimensión humana si esto es económicamente conveniente, por lo que considera inaceptable que el rol de educadores y educadoras se oriente hacia ajustarle en calidad de apéndices de las máquinas o en razón de la satisfacción de los servicios por los que estarían dispuestos a pagar los sectores económicamente poderosos, obviando con ello que la educación debería estar en razón de crear condiciones para el desarrollo de la personalidad de manera integral, socialmente comprometida con el bien común.

Para Freire, el rol docente se debería caracterizar por ser un transmisor de cultura que favorezca en el estudiantado el desarrollo de la capacidad para asumir responsablemente la toma decisiones, ser personas autónomas y creativas en el esfuerzo por transformar su realidad, lo que significa, que a pesar de la globalización, el personal docente debe mantener la esperanza de que el acto pedagógico se oriente hacia el ser humano y no hacia el aparato productivo. 
Desde esta perspectiva, considerar el acto educativo como un proceso de enseñanzaaprendizaje refuerza el criterio ideológico que pone a la enseñanza por encima del aprendizaje, propio del positivismo y facilita hacer de la educación un proceso instructivo para el desarrollo de habilidades y destrezas específicas en calidad de especialización, tal y como lo demanda la economía globalizada, de ahí la importancia de plantear un cambio de paradigma centrado en el aprendizaje-enseñanza, donde el aprender sea prioritario y, por ende, el enseñar tenga que ser replanteado en términos de la construcción de espacios de interacción social que potencien el quehacer estudiantil y no de la mejor exposición posible de la información.

Por último, con base en Pedagogía de la autonomía, se puede afirmar que sí se puede encontrar esperanza en la educación, siempre y cuando el docente asuma el compromiso de verse a sí mismo como agente de cambio social, lo cual descansa en que llegue a comprender y actuar con base en las siguientes consideraciones:

- Formar es mucho más que mostrar al estudiantado la información que precisa ser convertida en conocimiento, por lo que el quedarse en el nivel de presentar información contribuye a adiestrarlo en el desempeño de destrezas y habilidades y, por lo tanto, es hacerle el juego a la globalización.

- Nuestra capacidad de aprender descansa en el hecho de que somos seres inconclusos que pueden mejorar, lo cual solo es posible lograrlo en sociedad de manera compartida. Somos seres condicionados por las condiciones materiales de vida, pero ello no obliga a que estemos determinados por estas. Construimos en conjunto la historia y, a la vez, somos sujetos de ella, no objetos del modelo de producción.

- La reflexión crítica sobre la relación entre la teoría y la práctica es una necesidad para que la teoría no es convierta en palabrería y la práctica en activismo. La reflexión es el recurso para la superación de la condición inconclusa, para estimular la investigación de manera permanente y cotidiana

- Enseñar no es transferir conocimiento, sino crear las posibilidades de su producción o su construcción, de ahí la necesidad e importancia de conocer cómo aprende el estudiantado para trabajar en la dirección aprendizaje-enseñanza. Solo el aprendizajeenseñanza posibilita el respeto a las demás personas, porque obliga a tomar consciencia de su presencia, a articular el decir con el hacer y el actuar éticamente

- Quien forma se forma y reforma al formar y quien es formado se forma y forma al ser formado, por cuanto el acto educativo es dialógico y compartido, merced al carácter inconcluso del ser humano.

- Cuanto más críticamente se ejerza la capacidad de aprender, tanto más se construye y desarrolla la capacidad de investigar; aspecto imprescindible para saber enseñar y poder construir el conocimiento.

\section{Referencias}

Altarejos, F. y Naval, C. (2004). Filosofía de la educación. España: Ediciones Universidad de Navarra. 
Amado, M., Brito, R. y Pérez, C. (2007). Estilos de aprendizaje de estudiantes de educación superior. Instituto Tecnológico de Mexicali. Universidad Autónoma de Baja California. Recuperado de www.alammi.info/revista/numero2/pon 0011.pdf

Bonilla, F. (1998). Estilos de aprendizaje de los estudiantes de la Universidad de Costa Rica. Educación, 12(1), 17-26. doi: http://dx.doi.org/10.15517/revedu.v12i1.20291

Carr, N. (2011). Superficiales ¿Qué está haciendo el internet con nuestras mentes? México: Taurus.

Casassus, J. (2006). La educación del ser emocional (1ํ ed.). Universidad Virtual del Instituto Tecnológico de Monterrey. Monterrey: Ediciones Castillo.

Escontrela, R. y Stojanovic, L. (Septiembre, 2004). La integración de las TIC en la educación; apuntes para un modelo pedagógico pertinente. Revista de Pedagogía, 25(74), Recuperado http://www.scielo.org.ve/scielo.php?pid=s0798-97922004000300006\&script=sci arttext

Freire, P. (1998). Pedagogía de la autonomía. Saberes necesarios para la práctica educativa. México: Editorial Siglo XXI.

García, J. (2012). La educación emocional, su importancia en el proceso de aprendizaje. Revista Educación 36(1), 97-109. Doi: http://dx.doi.org/10.15517/revedu.v36i1.455

García, J. (2014). Educación, sociedad del conocimiento y tecnologías digitales, de lo conflictivo a lo complementario. Ponencia presentada ante el V Taller Internacional "La Virtualización en la Educación Superior. $9^{\circ}$ Congreso Internacional de Educación Superior, Universidad 2014. La Habana, Cuba.

Hopenhayn, M. (1987). Ruptura o refuerzo: una ambigüedad vigente. A propósito de "La condición postmoderna" de J. F. Lyotard". Estudios Públicos $N^{o} 27$. Recuperado de www. cepchile.cl/dms/archivo 1872 78/rev27 hopenhayn.pdf

Lampert, E. (2008). Postmodernidad y universidad. Una reflexión necesaria. Perfiles educativos, 30(120), 79-83. Recuperado de redalyc.uaemex.mx/src/inicio/ArtPdfRed. isp?iCve $=13211159005$

Martínez, P. (2008). Estilos de aprendizaje: Pautas metodológicas para trabajar en el aula. Revista Complutense de Educación, 19(1), 77-94. Recuperado de http://revistas.ucm.es/ index.php/RCED/article/view/RCED0808120077A

Millar, V. (2007). Pedagogía de la autonomía por Paulo Freire. Learning to learn. Recuperado el de https://veronicamillarreyes.wordpress.com 
Nevot, A. (2001). Estilos de aprendizaje y enseñanza de las matemáticas. Recuperado de www.estilosdeaprendizaje.es/ANevot.pdf

Organización para la Cooperación y el Desarrollo Económico. (2010). Habilidades y competencias del siglo XXI para los nuevos aprendices del nuevo milenio en los países de la OCDE. Recuperado de http://recursostic.educacion.es/blogs/europa/media/blogs/ europa/informes/Habilidades y competencias siglo21 OCDE.pdf

Picardo, O. (Mayo - agosto, 2002). Pedagogía informacional: Enseñar a aprender en la sociedad del conocimiento. Revista Iberoamericana de Ciencia, Tecnología, Sociedad e Información, 3. Recuperado de www.oei.es/revistactsi/numero3/art04.htm

Therer, J. (1998). Styles d'enseignement, styles d'apprentissage et pédagogiedifférenciée en sciencies. (Estilos de enseñanza, estilos de aprendizaje, diferenciados en ciencias). Université de Liège. Laboratoried'enseignement Multimedia. Informations Pédagogiques $\mathrm{n}^{0}$ 40. Recuperado de www.restode.cfwb.be/download/infoped/info40a.pdf 